\title{
The Exploration of the Sustainable Development
}

\author{
Xiaohui Sun ${ }^{1}$ \\ ${ }^{1}$ School of Environmental Science and Engineering Department, North China Electric Power \\ University, Baoding 071003, China; \\ asunxiaohui77@126.com
}

Keywords: Sustainable development; MCMC; PCA; Ecology; GWP

\begin{abstract}
Sustainable development, as an economic developing model focusing on long-term development, can balance the contradiction between economic development and ecosystem's healthy development. In our report, we take 24 indexes in four aspects, namely social, economy, resource and environment, and remain the main influence of indexes by Principal Component Analysis (PCA) to analyze a country's ability of sustainable development in Sustainable Balance Degree Model.

Ecological environment is decisive factor of the sustainable development, the influence of environmental factors is different on the ecological dynamics, so by the weight of different factors, adopts the GWP says pollution factors, to calculate the pollution from all countries value, judge their state of sustainable development.
\end{abstract}

\section{Introduction}

Is it necessary that the high development of the world's economy be in contradiction with sustainable development? In the last few decades, the development of the world's economy, especially for those developing countries, has been tracing for the single goal of the growth of economy, as it's the only way to get rid of poverty in their point of view. However, the rough model of growth in economy has not brought them the higher efficiency in developing economy whilst caused damage to the environment. But in 1987, Brundland Report defined sustainable development as "development that meets the needs of the present without compromising the ability of future generations to meet their own needs" [1]. Based on all these factors, we might get some hints.

The concept of sustainable development has a long history in scientific world. Early in 1713, Hans Carl Von Carlowitz coined the word in order to meet the challenge of a predicted shortage of timber, the key resource of the time ${ }^{[2]}$. In recent years, as the deterioration of the environment has increased gradually and the resource becomes less, the world just start to realize that how important is sustainable development for us. Sustainability requires the poverty eradication, the promotion of social equity, changing the unsustainable model into a sustainable model, which can enhance the ability of consumption and production.

Based on the above, this paper proposes a method, to measure the ability of a country's sustainable development, to help policymakers better judge, help people better understand their situation. At the same time, due to the ecological environment is the decisive factor of sustainable development, so this paper extends a new measurement method of sustainable ecological aspects.

\section{Sustainable Balance Degree Model}

The overall train of thought. Exploring the indicator system of sustainability and measure is of scientific and practical significance. By doing so, it can help provide the decision makers with information on how the complex system of the nature and economic society operates in short-term and long-term and can also provide support for decision making ${ }^{[3]}$. In order to assess a country's sustainable level, we choose 24 indexes from the four main aspects including social, economy, resource and environment.

According to the cask effect, for a wooden basket, which is made of by different length of wood, the shortest piece of wood is the one decides how much water it can hold. So as for a country, the 
short in any resource could not be made up by else resources (for instance the shortage of water can not be made up by other resource like oil.) Thus, we think the sustainable development should follow the following rule:

$$
w_{i}^{(j)}<w_{i} \quad i=1,2,3 \ldots
$$

Where $\mathrm{w}_{\mathrm{i}}{ }^{(\mathrm{j})}$ stands for the sustainable element $\mathrm{i}$ of country $\mathrm{j}$, Wi is the threshold of sustainable element i following the sustainable development's requirement, and the specific value of Wi can be obtained in the related principles from the UN.

It's possible that we might set a relatively strict function where there is no country in the world can be in a sustainable condition. However we could also use the 24 indexes to compare those unsustainable countries with each other so that we could finally get the result of which country is more sustainable whereas which is not.

Explanation of Index. We define $A_{k}(k=1,2,3,4)$ as the first-degree indexes which include social index, economic index, resource index and environment index. Furthermore, there are second-degree indexes under each index in the first-degree ones, which is defined as $A_{\mathrm{kq}}$. The four major aspects of indexes, which are 24 items in total, are shown as follow:

Table 124 indexes in assessment of a country's sustainable level

\begin{tabular}{|c|l|}
\hline \multirow{5}{*}{ Society } & Poverty headcount ratio at national poverty lines (\% of population) \\
Health expenditure, total (\% of GDP) \\
Unemployment, total (\% of total labor force) \\
Population density (people per sq. km of land area) \\
Literacy rate, adult total (\% of people ages 15 and above) \\
Employment in industry (\% of total employment)
\end{tabular}

Among all these indexes, we lack some related data. It can be calculated by Markov Chain Monte Carlo Techniques (MCMC) or Regression-based Modeling. After testing, we find it might be better to use the MCMC approach. 
PCA Algorithm. Principal component analysis (PCA) is a statistical procedure that simplifies dataset. The number of principal components is either less than or equal to the number of the original variables. This transformation is defined in such a way that the first principal component has the largest possible variance (that is, accounts for as much of the variability in the data as possible), and each succeeding component in turn has the highest variance possible under the constraint that it is orthogonal to the preceding components ${ }^{[4]}$.It is a effective method to reduce the dimensions.

In short, it includes five steps:

Step 1: Normalize the data of indicators.

Collect $\mathrm{P}$-dimensional random vectors $\mathrm{X}=\left(\mathrm{X}_{1}, \mathrm{X}_{2} \ldots \mathrm{X}_{\mathrm{P}}\right)^{\mathrm{T}}$ and $\mathrm{n}$ samples $\mathrm{xi}=\left(\mathrm{x}_{\mathrm{i} 1}, \mathrm{x}_{\mathrm{i} 2}, \ldots, \mathrm{X}_{\mathrm{ip}}\right)^{\mathrm{T}}$. Then we should make the sample matrix. Normalize the sample matrix as follows:

$$
Z_{i j}=\frac{x_{i j}-\bar{x}_{j}}{s_{j}} \quad(i=1,2, \ldots n ; j=1,2, \ldots p)
$$

Where $\bar{x}_{j}$ is the average of $\mathrm{x}_{\mathrm{ij}}$ from $\mathrm{i}=1$ to $\mathrm{i}=\mathrm{n}, \mathrm{s}_{\mathrm{j}}$ is the variance of $\mathrm{x}_{\mathrm{ij}}$ from $\mathrm{i}=1$ to $\mathrm{i}=\mathrm{n} . \mathrm{Z}$ is the normalized matrix.

Step 2: Calculate the correlation coefficient matrix of $Z$.

$$
R=\left[r_{i j}\right] x p=\frac{Z^{T} Z}{n-1}
$$

Where $r_{i j}=\frac{\sum z_{k j} \cdot z_{k j}}{n-1} \cdot \mathrm{R}$ is the sample correlation matrix.

Step 3: Solve the characteristic equation of sample correlation matrix $\mathrm{R}$ and get $\mathrm{p}$ characteristic roots $\lambda$.

Based on $\left|R-\lambda I_{p}\right|=0$, we can determine the value of $m$. Make information utilization ratio of more than $85 \%$.

$$
\frac{\sum_{j=1}^{m} \lambda_{j}}{\sum_{j=1}^{p} \lambda_{j}} \geq 0.85
$$

Solve the equations of $R b=\lambda_{j} b$ and we can get the unit eigenvector $b_{j}{ }^{\circ}$.

Step 4: Change the normalized index variables into principal component.

$$
U_{i j}=z_{i}^{T} b_{j}^{o}(j=1,2, \ldots m)
$$

$\mathrm{U}_{1}$ is the first component, $\mathrm{U}_{2}$ is the second principal component,..., $\mathrm{U}_{\mathrm{p}}$ is the pth principal component.

Step5: Evaluate m principal components.

From the table 1, there are too many second-degree indexes. In order to determine the influences of second-degree indexes on the first-degree index, we should remain the main influence and set the secondary influence aside. For each second-degree index corresponding to the second-degree index, if it is a positive-impact index, we remain it. If it is a negative-impact index, we take its reciprocal. Based on PCA, we can get the evaluation results of second-degree indexes and get the value of first-degree indexes. The social index and economy index are used to measure the level of a country's development whereas the resource index and environmental index mainly reflect the level of a country's sustainable development. We set the weight of the first two 0.15 respectively and the weight latter two 0.15. By calculating the weighted mean, we can get the sustainable balance degree.

By followed the method above, we can know the level of sustainable development. With the bigger value of sustainable balance degree, the country is more sustainable.

A method of measuring sustainable ecological aspects. Since not all pollutants damage the environment and peoples health as much as others, each would be individually weighted by a value indicative of the its current yearly damage on the environment. So a final measurement of the ecological aspect of sustainability would be a weighted pollution index.

There, we use the theory of L.D. Danny Harvey, Global warming potential, or GWP, is a measure of how much heat - which damages the environment through global warming - is entrapped in the 
environment due to an atmospheric pollutant ${ }^{[5]}$. GWPs of various greenhouse gases are calculated based on the amount of heat they trap relative to the amount of heat trapped by the same mass of CO2 gas (whose GWP is normalized to 1) over a specified time frame ${ }^{[6]}$. The Intergovernmental Panel on Climate Change (IPCC) and Kyoto Protocol both use GWP measures as the de facto standard to measure emission damage when creating environmental policy ${ }^{[7]}$. So we can use the GWP values to get country emission data. For the country we research, we can calculated its' pollution $Q$ as:

$$
Q=\sum_{p}^{\text {pollutants }} M_{p} * N_{p}
$$

Where $\mathrm{M}$ is amount of pollutant $\mathrm{p}$ emitted per capita and $\mathrm{N}$ is the damage-based weighting of that pollutant based on normalized GWP data. The result is that, we combined the pollution data with normalized nonrenewable energy use per capita data equally, to measuring a country's sustainable ecological aspects. Due to the space, here only a brief introduction on the thought.

\section{References}

[1] Burton I. Report on Reports: Our Common Future: The World Commission on Environment and Development [J]. Environment: Science and Policy for Sustainable Development, 1987, 29(5): 25-29.

[2] A/68/970 - Report of the Open Working Group on Sustainable Development.

https://sustainabledevelopment.un.org/sdgsproposal

[3] Kates R, Clark W C, Corell R, et al. Sustainability science [J]. Science, 2001,292(4): 641-642

[4] Principal component analysis.http://wiki.mbalib.com/wiki/PCA

[5] S. J. Smith and M. L. Wigley. Global warming potentials: Climatic implications of emissions reductions. Climate Change, 44(4): 445-457, 2000.

[6] D. Albritton, R. Derwent, I. Isaksen, M. Lal, and D. Wuebbles. Radiative forcing of climate $\square$ change. Climate Change 1995, The Science of Climate Change, pages 118-131, 1996.

[7] S. J. Smith and M. L. Wigley. Global warming potentials: Climatic implications of emissions reductions. Climate Change, 44(4):445-457, 2000. 